\title{
EFFECT OF DiFFERENT TYPES OF PAINT TO RESIDENTIAL BUILDING
}

\author{
Nurshafina Sharkawi ${ }^{1}$ and Azhaili Baharun ${ }^{2}$ \\ 1 Executive College, 2nd Floor, Crown Square, 88, Jalan Pending 93450 Kuching, Sarawak, Malaysia \\ 2 Department of Civil Engineering' Faculty of Engineering, Universiti Malaysia Sarawak, 94300 Kota Samarahan, \\ Sarawak, Malaysia
}

Date received: 25/07/2016, Date accepted: 25/09/2016

Corresponding author's email: nurshafina@ecollege.edu.my

\begin{abstract}
In recent years, Malaysia has experienced climate change that leads to the higher consumption of energy due to the increasing outdoor temperature that affects indoor discomfort conditions. Paints were found to be the insulation material that is increasingly important because of their benefits in terms of thermal comfort and energy savings. Therefore, the aim of this study is to determine the effect of different types of paint to the residential building. Two types of paints were applied on indoor walls of identical room and their performance was compared. The equipment used to measure the performance includes data logger and thermocouple for temperature performance and lux meter for illumination performance. The experiments consider the impacts of paints on interior surface temperature, wall orientation, indoor air temperature and the illuminance level. The result shows that the air temperature of the room was brought down considerably at about $1.9^{\circ} \mathrm{C}$ by implementing the reflecting paint on the indoor walls. The most significant effect is on the surface temperature with the highest temperature reduction of about $2.8^{\circ} \mathrm{C}$ which occurs at west wall after the application of reflective paint that makes it as the best location to use reflective paint. For illumination, the results show that reflective paint gives significant effect compare to energy saving paint with the highest illuminance level of 392 lux. With the application of reflective paint, the indoor temperature is improved and thus minimized the energy usage. Reflective paint has also presented the ability to reduce the indoor temperature, the effective wall orientation when applying it and improves the illuminance level of indoor building.
\end{abstract}

Keywords: Climate change, Reflective paint, Temperature, Illumination.

\subsection{INTRODUCTION}

$\mathrm{T}$ The changes in climate has led to indoor discomforts, which indirectly affects the energy usage. When the outdoor air temperature increases, a building will experience indoor discomfort conditions and this will lead to the critical demands of mechanical ventilation [1]. Climate change has caused impacts on the air conditioning system and brings a significant effect on the building's cooling and heating load, the electricity consumption and the outdoor design conditions for the air conditioning system globally [2].

A study on the impact of the climate change on power consumption was done in Bangkok in year 2006 found out that the increasing of $1^{\circ} \mathrm{C}, 2^{\circ} \mathrm{C}$ and $3^{\circ} \mathrm{C}$ temperature cause the increasing usage of power consumption up to $21.45 \%$ (see Table 1). Although the rise of the temperature is in a small amount, however the modest increase affect the household power consumption. Thus, this shows that climate change had demand the maximize usage of the electricity especially in the hot and humid climate which is caused by the increasing usage of air conditioners in order to provide thermal comfort for the users.

Building is the major energy consumers in Malaysia where electricity was found to be the major consumer in a building [3] and [4]. The increase in electricity use by the residential sector particularly in hot and humid periods has been caused by the growing demand for air conditioners to provide thermal comfort for the occupants. Since Malaysia is known as a country with hot and humid climate, this could be the ultimate reason for indoor thermal discomfort to occur. Therefore, effective strategy is 
needed to be adopted in order to reduce the extra heat going into a building and improve the thermal discomfort condition that affects the occupants. Although air conditioning is one of the solutions to overcome the thermal discomfort problem, however it consumes a lot of energy and money.

Table 1: Impacts of Climate Change to the Power Consumption in Bangkok (Yau and Pean, 2011)

\begin{tabular}{|c|c|c|c|c|c|}
\hline Month & $\mathrm{I}_{n}\left({ }^{\circ} \mathrm{C}\right)$ & $\mathrm{EC}$ (actual) & $\Delta \mathrm{EC}\left(\mathrm{I}_{\mathrm{a}}+1\right)(\mathrm{GWh})$ & $\Delta E C\left(T_{\mathrm{a}}+2\right)(G W h)$ & $\Delta \mathrm{EC}\left(T_{a}+3\right)(\mathrm{GWh})$ \\
\hline January & 27.9 & 611.73 & 87.26 & 140.05 & 192.84 \\
\hline February & 29.4 & 684.67 & 102.5 & 15529 & 208.08 \\
\hline March & 30.2 & 818.88 & 30.71 & 835 & 136.29 \\
\hline April & 30.8 & 834.28 & 45.32 & 98.11 & 150.9 \\
\hline May & 30.1 & 811.53 & 80.06 & 13285 & 185.64 \\
\hline June & 29.4 & 788.96 & 55.03 & 107.82 & 160.61 \\
\hline July & 29.5 & 766.34 & 61.06 & 113.85 & 166.63 \\
\hline August & 29.2 & 766.85 & 31.36 & 84.15 & 136.94 \\
\hline September & 28.8 & 772.81 & 34.34 & 87.13 & 139.92 \\
\hline October & 29.2 & 745.37 & 85.92 & 138.71 & 191.5 \\
\hline November & 29.9 & 781.77 & 59.95 & 11274 & 165.52 \\
\hline December & 27.5 & 695.97 & 7.18 & 5996 & 112.75 \\
\hline Average & & 756.6 & 5672 & 109.51 & 162.3 \\
\hline KChange & & & 7.49 & 14.47 & 21.45 \\
\hline
\end{tabular}

Based on the studies presented, it is clear that climate change greatly affected the energy usage. Therefore, measures related to cooling and heating loads have become particularly important, and there is a trend toward improving building coatings to reduce the effect of the outside environment and to allow cooling and heating equipment to be used in an efficient manner. Heat propagated in interior spaces is through roofs and walls and partly through ceiling and ceiling panels by the process of conduction and radiation. In order to reduce the heat, material of tolerable thermal is needed to be used in the building components such as roof and wall [5].

Reflective paint is becoming increasingly important as it offers benefits in thermal performance and energy saving when it is applied to the building components. It is known as a cool material due to its optical properties that stay cooler compare to standard materials [6]. Reflective paint also was found able to reduce the temperature up to $7^{\circ} \mathrm{C}$ and thereby reducing the usage of air conditioning and fans [5]. Besides that, application of the reflective paint on corrugated roof reduces ceiling temperature up to $8^{\circ} \mathrm{C}$ and $10^{\circ} \mathrm{C}$. Indoor temperature also had reduced up to $2.8^{\circ} \mathrm{C}$ and $4^{\circ} \mathrm{C}$. Thus, drop in the ambient air temperature due to the application of reflective thermal coating improves the indoor thermal comfort condition [7]. Therefore, a good thermal coating like reflective paint could be a good solution in improving the thermal performance and energy saving of a building.

\subsection{MotiVATION}

Based on the studies presented in the previous section, it is clear that the climate change greatly affected the energy usage. Due to this, paint as materials use for building plays an important role in order to overcome these phenomena. However, there were various type of paint and each type gives different effect to the building. Therefore, this research intends to determine the effectiveness of different types of paint to lower down the temperature which leads to the energy usage reduction in a building. This research also will discover the most effective wall orientation after the application of the paint. The effectiveness of the paints in improving the illuminance level in the room will also be measured.

Furthermore, nowadays, there has been a growing innovation on heat-resistant or heat-insulating paint that claims for improvement of energy-saving performance. However, some of the paints require 
different mechanism of installation in order for the paint to perform very well in improving the thermal performance. This shows that the manufacturer is presently using its own proprietary standards to evaluate energy savings. Therefore, a common method of quantitative evaluation is desirable.

\subsection{EXPERIMENTAL PROCEDURES}

This study has been carried out using two identical rooms of residential building that is located at Kampung Datuk Ajibah Abol. The case study was conducted at 7.30 am to $6.30 \mathrm{pm}$. Two types of paint were used which are reflective paint and energy saving paint. The physical parameters that were considers in this study to determine the effects of the paints includes air temperature, surface temperature and illuminance level. Before the application of the paints, the thermal performance of both room were analyzed for three days using thermocouple and data logger. This is to ensure that the thermal performances of both rooms are similar so that the comparison on effects of both paints can be made. Figure 2 below shows how the assessment is done.

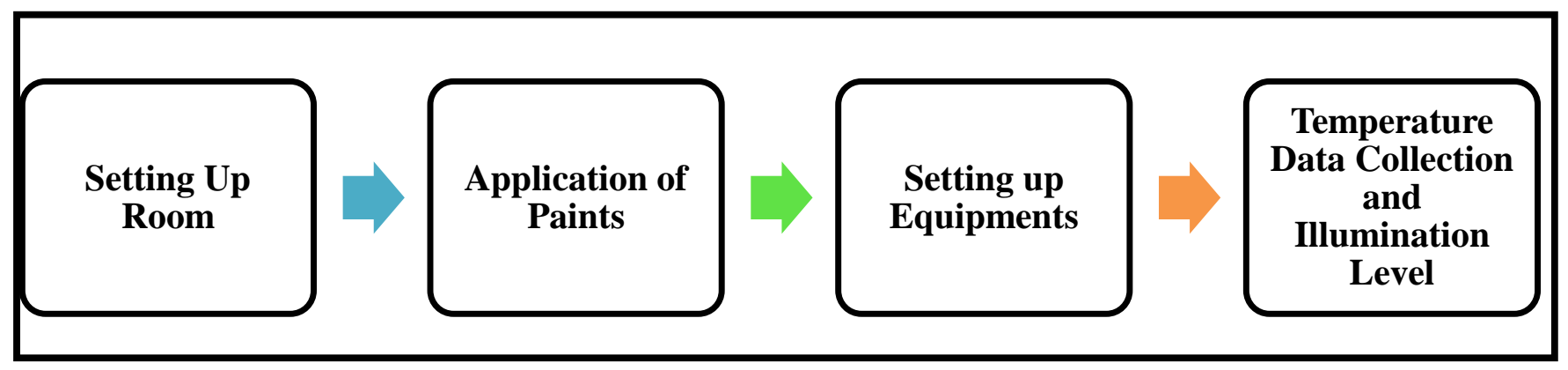

Figure 2 Flowchart of Data Collection Sequence

The single story modern house selected for the study is also located in the village that is situated in the centre of city of Kuching. A diagram of the house is shown in Figure 3(a). The roof is made of metal deck insulated and the door is timber swing door type. The wall is made of red brick plaster and ceiling is made of ceiling board. The house consists of 3 bedrooms, 1 toilet, 1 living room and 1 kitchen. The actual experimental room is Room 1 and Room 2. Floor area of Room 1 is $7.49 \mathrm{~m}^{2}$ and Room 2 is 7.2 $\mathrm{m}^{2}$. The glazing area for both rooms is identical with area of $1.5 \mathrm{~m}^{2}$. The layout of the room is depicted in Figure 3(b).

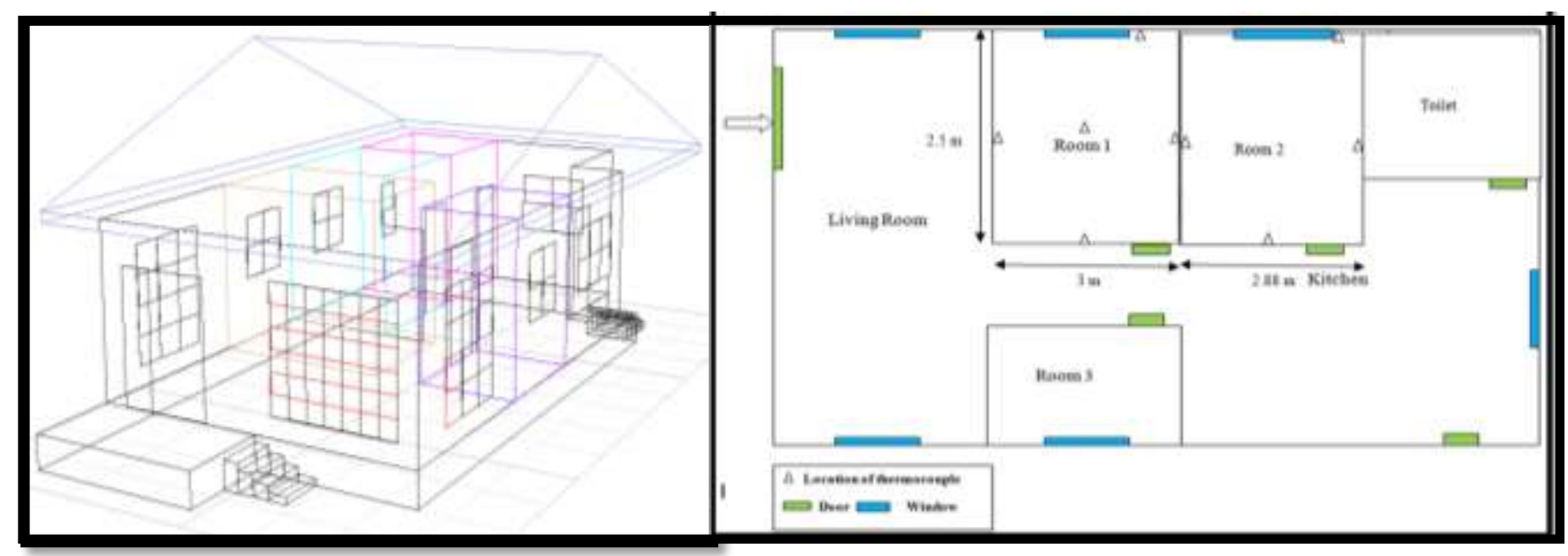

Figure 3(a) Experimental House

Figure 3(b) Sketch of the house layout used in experimental works (not to scale) 
The analysis on the thermal performance and the illumination effect of both paints will be presented using graphs where the experimental works were conducted for 11 hours from 7.30 am to $6.30 \mathrm{pm}$. The thermal performance of both paints were measured based on the impact on air temperature, surface temperature and wall orientation. In order to determine the effect of the paints, similar performances of experimental rooms are needed. This is to ensure that the thermal performances of both rooms are similar so that the comparison on effects of both paints can be made. From the data analysis, it can be conclude that both rooms are suitable for the experimental works to determine the effect of the paints as both rooms shows similar thermal performance and illuminance level with less than $5 \%$ difference

\section{A. Air Temperature}

Air temperature is a parameter that measured the surrounding temperature. It is very important in determining and monitoring the effect and thermal performance of the paint. For this study, the air temperature was measured using thermocouple that was covered with aluminium foil to avoid the heat radiation from surroundings that might lead to error in temperature readings. The thermocouple was placed $1.0 \mathrm{~m}$ from floor in the centre of the room. During the 5 days observation, 2 days were chosen as the better days in terms of clear skies to get the better results. The results of air temperature reading for both energy saving paint and reflective paint are shown in the graph as depicted in Figure 4.

From the graph, it shows that reflective paint shows significant effect compare to energy saving paint. The graph of air temperature of room with reflective paint mostly shows lower temperature than the energy saving paint with highest difference recorded is $1.9^{\circ} \mathrm{C}$. In general, the difference in structural temperature inside and outside the room becomes large as the insulation performance improves. This shows that the performance of reflective paint is better as it consists of glass beads that help to reflect the solar radiation back into the atmosphere resulting in the reduction of heat loading and dissipates heat.

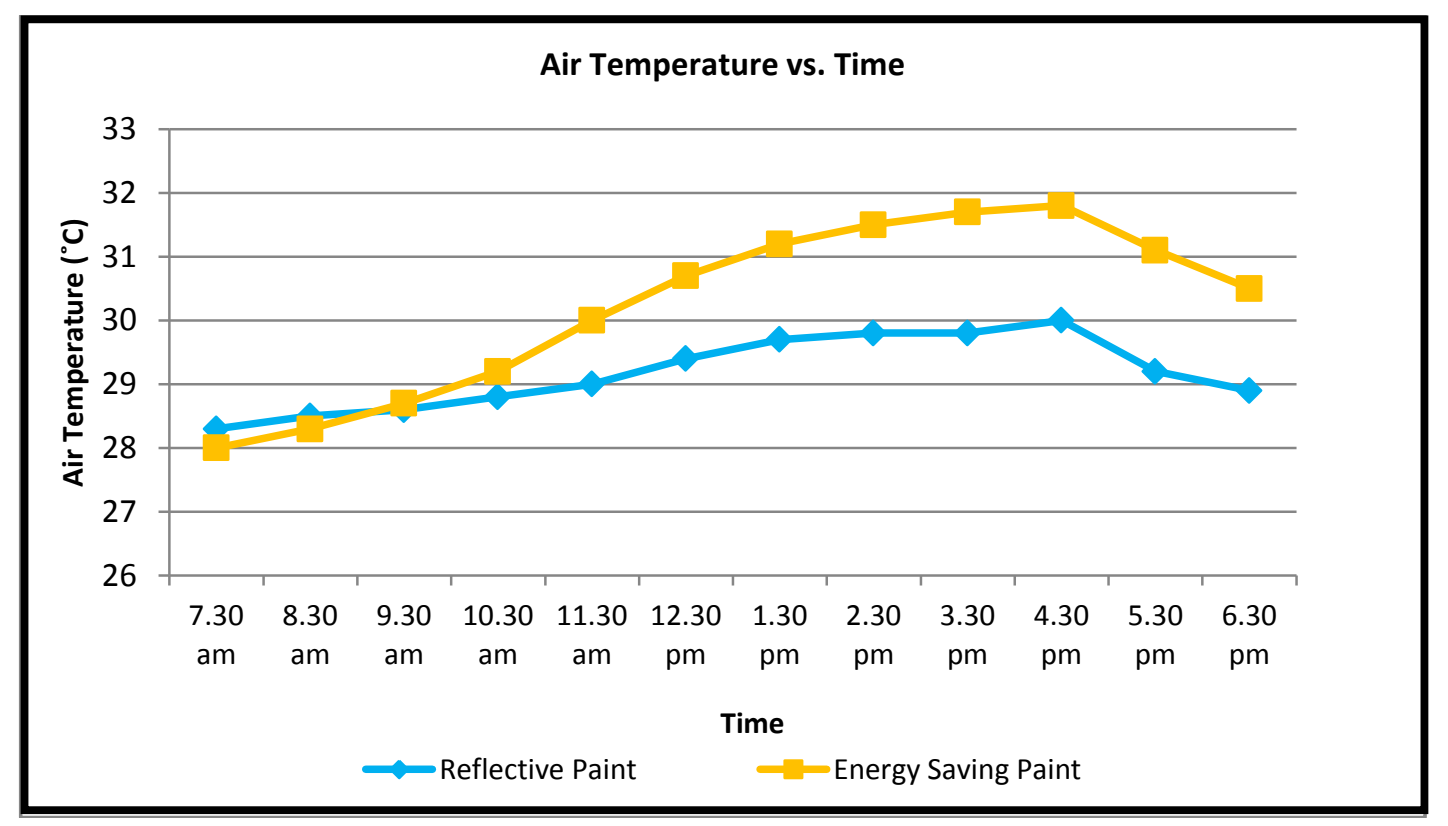

Figure 4: Graph of Air Temperature 


\section{B. Surface Temperature}

Surface temperature is very important as it will determine the thermal performance of the paint on building envelope. The results of surface temperature measurement using energy saving paint and reflective paint are computed in the graph shown below. For this study, 4 wall surfaces had been attached with thermocouple to determine the surface temperature. The building surfaces include north wall, south wall, west wall and east wall. During the measurement period, data was collected from 7.30 a.m to 6.30 p.m. The detailed measurements of surface temperature are presented in graphs as shown in Figure 5

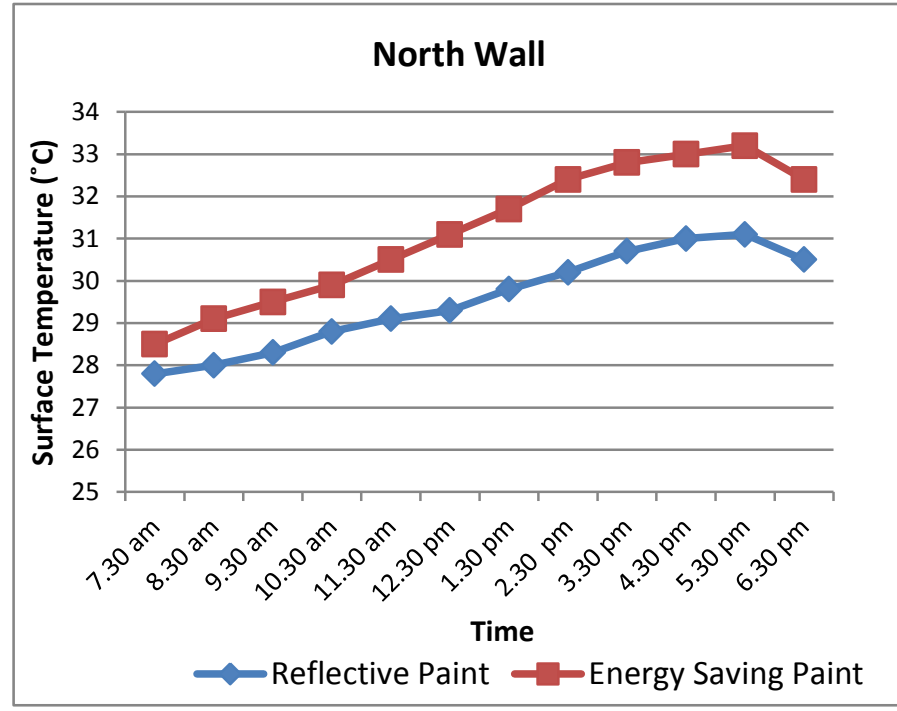

Figure 5 (a): North Wall Surface Temperature

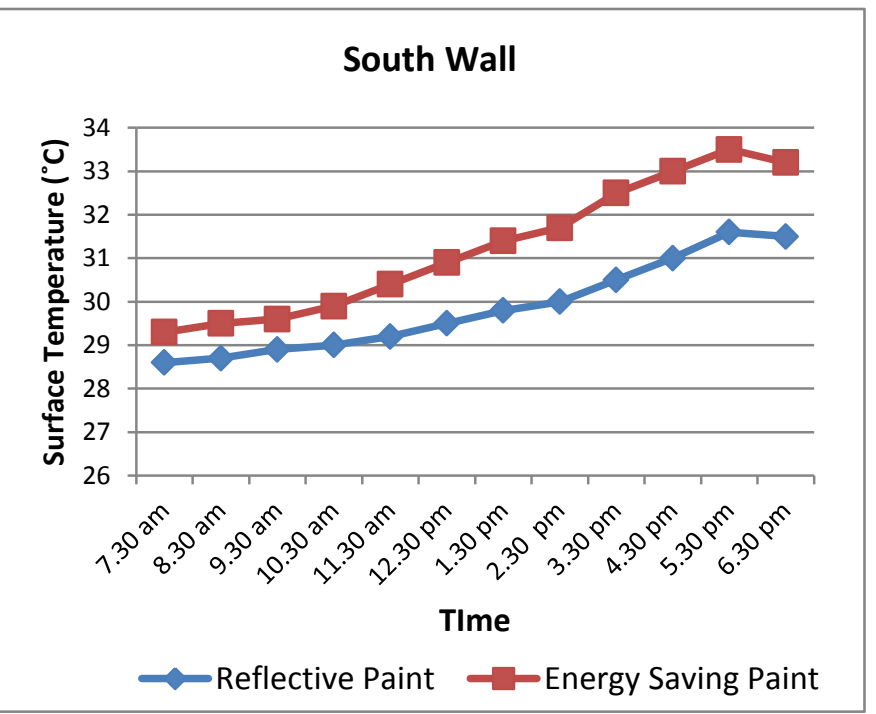

Figure 5 (b): South Wall Surface Temperature

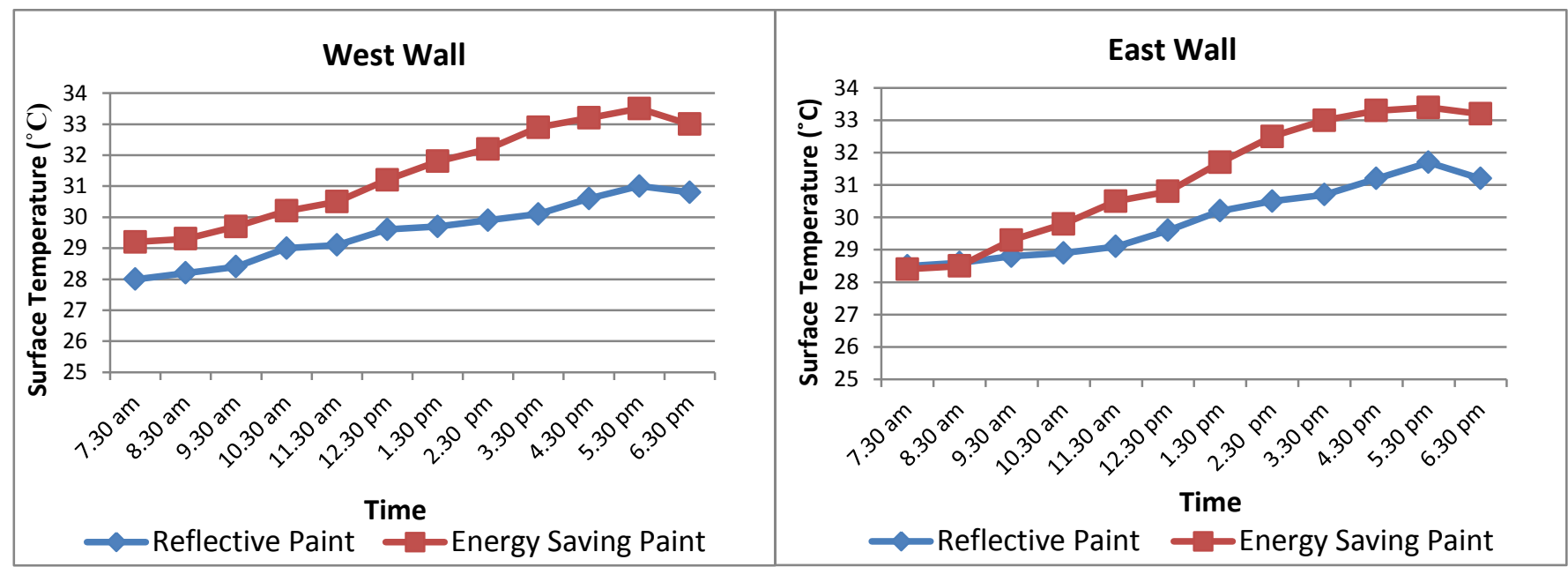

Figure 5 (c): West Wall Surface Temperature

Figure 5 (d): East Wall Surface Temperature

From the results presented above, it shows that reflective paint have a significant effect on surface temperature compare to energy saving paint. For north wall, the maximum different of surface temperature is $2.2^{\circ} \mathrm{C}$. The maximum different of surface temperature south wall is $1.7^{\circ} \mathrm{C}$. For east wall, the maximum different of surface temperature is $2.3^{\circ} \mathrm{C}$ meanwhile for west wall the maximum different 
of surface temperature is $2.8^{\circ} \mathrm{C}$. Therefore, the best location to use reflective paint is on west wall because the greatest reduction occurs at this orientation.

From the graphs, it should be noticed that the difference between energy saving paint and reflective paint surface temperature indicates the difference of surface heat gain. This indicates that reflective paint performance is better compare to energy saving paint in reducing heat. In addition to energy savings, it shows the potential of reflective materials to reduce heat gains and to improve thermal comfort in buildings.

\section{Illumination}

Illuminance is a measure of quantity of light that is distributed on a surface of area. To know the amount of light use is important because the excessive amount of light can affect human's eye. Different situation needs different level of illuminance where it is usually affected by the eye, speed and accuracy and places. Illuminance is a measure using a Lux Meter where the S.I. unit is Lux. Only one point in rooms were chosen which is in the middle of the room for internal illumination data which is taken simultaneously as there was a limit in the number of lux meter available. During the measurement period, the data was taken from 9 am to $3 \mathrm{pm}$ as the skies were not considered fully bright before 9 am and after $3 \mathrm{pm}$ extensive sunlight penetration occurrences in all rooms. During the 5 days observation, 2 days were chosen as the better days in terms of clear skies to get the better results. The illustration charts of the results are shown in Figure 6.

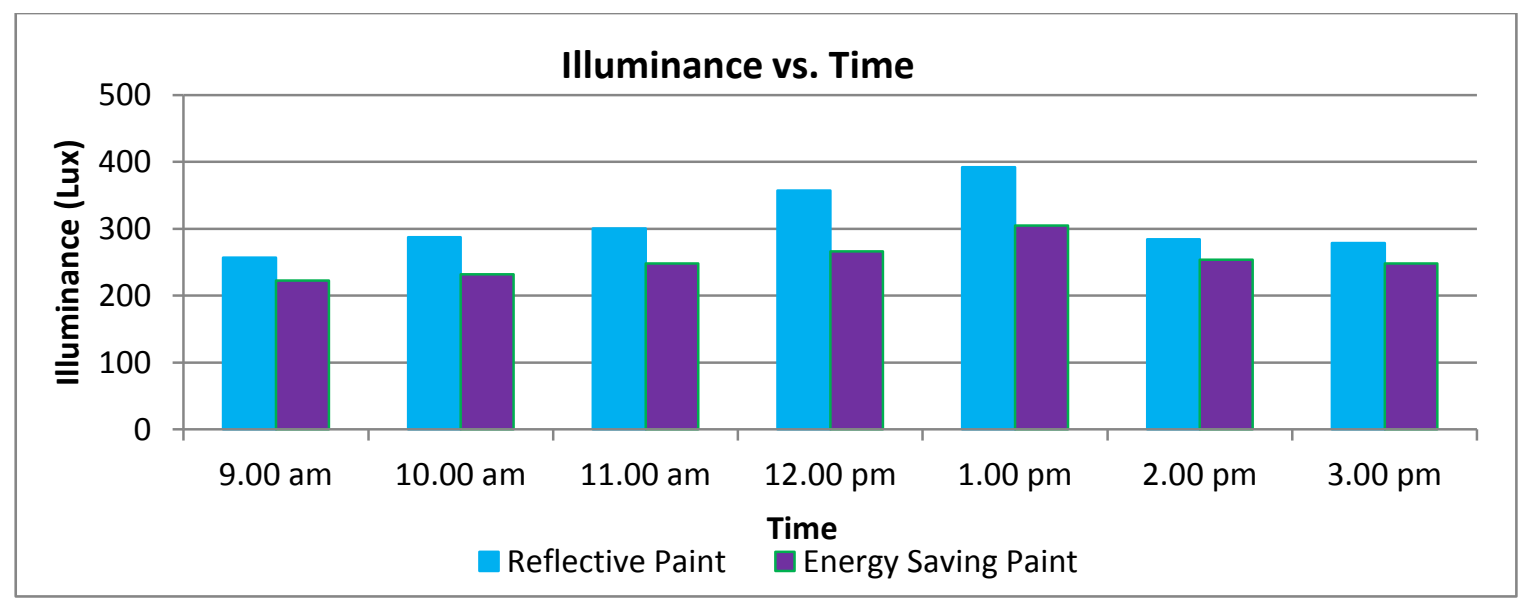

Figure 6: Lux Reading

From the results, it shows that reflective paint give significant effect on illuminance level. The illumination level for room with reflective paint range from 257 lux to 392 lux which was little higher than requirement of standard illumination in typical room according to Malaysian Standard- MS 1525 2001 which is 150 lux to 300 lux. Since the results of illuminance level is based on natural lighting, the glazing area (windows) could be considered as the factor as it lets in excessive light that might create glare problem and extra heat gain as well. To improve the illuminance level, the amount of light should be control with the usage of curtains, blinds or shading devices.

For energy saving paint, the illumination level for room range from 214 lux to 305 lux. Although the illumination is lower that the reflective paint, however the illuminance level is still within the range of standard illumination of typical room according to Malaysian Standard- MS 15252001 which is 150 lux to 300 lux. Thus, the glazed area for this room is suitable and no devices to control the amount of light that penetrate the room are needed. 


\subsection{CONCLUSIONS}

It is undeniable that reflective paints gives significance effect compare to energy saving paint which proves that different types of paint gives different effect. With its optical properties, reflective paints able to reflect the solar energy very well that give them advantage to stay cooler than standard materials especially under hot weather which leads to temperature reduction. Nevertheless, reflective paints seem to be overlooked with the appearance of various types of new technology paint with energy saving elements. As a whole, it can be concluded that the application of reflective paints influence the three factors the most compare to energy saving paint. The factors include air temperature, surface temperature, and illuminance level. Based on the results obtained from the current experiment, the conclusions can be drawn on surface temperature performance is reflective paint shows great reduction of $2.8^{\circ} \mathrm{C}$ which occur on west wall that makes west wall as the best orientation for application of reflective paint. For air temperature, it can be conclude that reflective paint performs very well compare to energy saving paint as it able to reduce the air temperature with highest difference of $1.9^{\circ} \mathrm{C}$ with one layer paint application at position $1 \mathrm{~m}$ high above the ground. Meanwhile for illumination performance, reflective paint shows the highest illumination level for room with 392 lux compare to energy saving paint with 305 lux.

\section{REFERENCES}

[1] Ismail, A., Hanim, M., \& Rahman, A. M. (2008). Using Green Roof Concept As A Passive Design Technology to Minimse the Impact of Global Warming

[2] Yau, Y. H., and Pean, H. L. (2011). The Climate Change Impact on Air Conditioner System and Reliability in Malaysia. doi:10.1016/j.rser.2011.07.059

[3] Noranai, Z., Kammalluden, M. N., Tun, U., and Onn, H. (2012). Study Of Building Energy Index In Universiti Tun, 1(2), 429-433.

[4] Sadrzadehrafiei, S., Mat, K. S. S., and Lim, C. (2009). Energy consumption and energy saving in Malaysian office buildings. Energy Consumption and Energy Saving in Malaysian Office Buildings, 152-156.

[5] Sekar, M., Sakthivel, M., Kumar, S. S., \& Ramesh, C. (2012). Attaining The Room Comfort By Solar Reflective, 8(5), 556-562. doi:10.3844/ajessp.2012.556.562

[6] Pérez, I. H., Álvarez, G., Xamán, J., Guillén, I. Z., Arce, J., \& Simá, E. (2014). Thermal performance of reflective materials applied to exterior building components - A review. Energy \& Buildings, 80, 81-105. doi:10.1016/j.enbuild.2014.05.008

[7] Suman, B. M., \& Verma, V. V. (2003). Measured Performance of a Reflective Thermal Coating in Experimental Rooms, 62(December). 